\title{
Drogas com maior potencial de uso na Esclerose Lateral Amiotrófica
}

\author{
Drugs with potential greater of use in Amyotrophic Lateral \\ Sclerosis
}

\section{Carlo Domênico Marrone}

Neurologista e Neurofisiologista Clínico, Ambulatório de Doenças Neuromusculares do Hospital São Lucas da PUCRS - Porto Alegre / RS.

A patogênese da Esclerose Lateral Amiotrófica (ELA) não está definida, tendo como principais possibilidades, a excitotoxicidade glutamatérgica sobre os neurônios motores, a disfunção mitocondrial, o estresse oxidativo, a agregação proteica, o déficit de transporte axonal, aliado a inflamação peri-neuronal, sinalização aberrante de fatores de crescimento e, provavelmente outras causas ainda não aventadas ou menos "votadas". Portanto, com inúmeras hipóteses, a ciência neurológica não sabe, verdadeiramente, a(s) causa(s) da ELA.

Para uma adequada terapêutica, o conhecimento das causas da enfermidade seria fundamental. Como visto acima, a etiologia não está definida, assim, está sendo necessário lançar mão de algumas estratégias para tentar novas terapêuticas. Entre estas estratégicas está a indução de animais mutantes com características clínicas semelhantes às da ELA humana, em especial a deficiência da enzima superóxido dismutase I, encontrada em uma forma de ELA familiar. Desta forma pode-se realizar estudos pré-clínicos na tentativa de desenvolver medicamentos com base nas teorias etiológicas acima expostas.

Outra estratégia para se encontrar outras drogas é a de, após escolhido o mecanismo causador a ser estudado, geralmente de forma prévia por estudos em animais, verifica-se no mercado se já há drogas existentes e licenciadas que se enquadrem no perfil de combate a possível etiologia em estudo. Desta forma pode-se iniciar testes clínicos com maior rapidez e grande economia.

Para exemplificar tal estratégia, pode-se tomar como base a seguinte premissa: a redução do nível de glutamamto ns sinpases se deveria ao aumento da captação dessa substância por células nervosas (astrócitos e gliócitos). Isso é mediado pela expressão de um transportador de glutamamto (EAAT2). Assim, foram avaliados 1040 compostos aprovados 
pelo FDA (Food and Drug Administration - Estados Unidos), sendo que 15 antibióticos apresentavam tal ação, iniciando-se estudos clínicos.

Em relação aos ensaios clínicos, vale a pena relembrar de forma sucinta que existem 04 fases para avaliar a droga em estudo. A fase I que verifica a tolerância e o metabolismo do fármaco. A fase 2 que procura doses adequadas, geralmente com poucos pacientes, uma espécie de estudo piloto. A fase III que determina, em um número bem maior de enfermos a eficácia e a segurança através da comparação e, posteriormente ao lançamento no mercado, a farmacovigilância, sendo a fase 4 (nem sempre realizada)

Foi assim com o Riluzole® que, mesmo com todas as limitações que não cabe aqui discutir, tenta diminuir a excitotoxicidade do Glutamato e a progressão da morte neuronal. Tal medicamento não será alvo de discussão nesta revisão.

A lista de novos fármacos que tentam auxiliar no combate a ELA é imensa, praticamente cada semana surge uma idéia nova. Para exemplificar, foi tomado como base 04 medicamentos seguindo as estratégias já referidas (vide tabela 1).

\section{COMPOSTO FASE ALVO}

\begin{tabular}{lcc}
\hline Minociclina & III & Neuro-Inflamação \\
Tamoxifen & II / III & Tox. Glutamato \\
Arimoclomol & I / II & Indução "Heat-Shock Proteins" \\
Fenilbutirato Sódico & I & "Morte celular" \\
\hline
\end{tabular}

Tabela 1. Exemplo de 04 drogas com potencial de uso na ELA.

\section{Minociclina}

A minociclina é um antibiótico (tetraciclina) com alta penetrabilidade no sistema nervoso central, podendo ser tomado por via oral, tendo passados por estudos fase I e II 
(Neurology, 62,May, 2004 e Neurogical Science, 26, 2005), estando em fase III de ensaio clínico com cerca de 400 pacientes. Tem como alvo a inibição a morte através da redução da ativação de enzimas pró-apoptose (redução da ação das caspases) e de enzimas próinflamação (redução da sintase do óxido nítrico e da COX-2). Foi encontrado retardo no início da patologia e o aumento da sobrevida em modelos animais de ELA. Teria uma excelente aplicabilidade na ELA, pois é bem tolerado pelos pacientes, poderia agir sinergicamente com o Riluzole, porém no estudo fase III, infelizmente não está sendo demonstrado a eficácia dos estudos pré-clínicos.

\section{Tamoxifeno}

Este medicamento é usado há muito tempo para tratamento de câncer de mama, competindo com receptores de estrogênio, além de inibir a Proteina-Kinase (PKC). Essa enzima é age em uma das vias da excitotoxicidade do glutamato e foi constatado que sua ação está anormalmente aumentada na medula de pacientes com ELA. Pode ser utilizado por via oral, estando em fase II, mostrando, em resultados preliminares, que doses de $20 \mathrm{mg} / \mathrm{dia}$, a sobrevida em 02 anos era de $73 \%$, contra $48 \%$ com doses menores. Está sendo indicado, mesmo que ainda não tenha sido estudo fase III (ex.: vide boletim informativo da Associação Brasileira de Esclerose Lateral Amiotrófica - ABRELA).

\section{Arimoclomol}

É uma droga que estimula a ação da "Chaperonas", que por sua vez são proteínas citoplasmáticas que agem na interação de proteína com proteína, fazendo com que haja prevenção de agregação proteica indesejável. Isso se dá por adequada conformação proteica, evitando agrupamento e enovelamento as mesmas. Portanto estimulam a reparação celular natural (Nature Neuroscience 2005;6:11-22). Além disso foi comprovado que a ação das "Heat Shock Proteins" ( que fazem parte da resposta corporal ao estresse) são ativadas com dificuldade pelos motoneurônios, assim fazendo que haja mais um fator de vulnerabilidade na ELA. O Arimoclomol ativaria o mecanismo de citoproteção das células sob estresse e retarda a progressão e aumenta a sobrevida em ratos mutantes SOD1, mesmo após iniciada a doença. Pode ser administrado por via oral, estando em fase II (Nature Medicine 2004;10:402-405). 
Em estudos pré-clínicos foi encontrado melhora na função muscular e aumento na sobrevida do motoneurônio em $22 \%$.

\section{Fenilbutirato Sódico}

É um fármaco utilizado em erros inatos do metabolismo (anti-hiperamoníaco), tendo um mecanismo de ação "multi-alvo", regulando a expressão gênica. Isso se deve ao fato de inibir a enzima histona deacetilase (que controla o "empaotamento"do DNA). A medicação seria uma espécie de "Chaperona química", promovendo ou modificando a estabilidade proteica. Em animais (ratos SOD1) há uma lentificação da progressão da doença pela regulação de proteína anti-apoptótica (Bcl-2), sendo administrado por via oral. Tem estudos fase I e II, existindo dados a favor contra conforme os estudos ou americanos ou europeus.

Como foi mencionado que os ensaios clínicos são realizados após terminados estudos em modelos animais, deve-se ter em mente que, para a ELA, tais modelos são baseados principalmente em ratos SOD1, portanto um tipo de ELA familiar. A ELA familiar corresponde a menos de $10 \%$ da ELA em humanos (Esporádica - 90\%). Além disso, os tratamentos nos estudos pré-clinicos, iniciam antes da doença estar instalada, o que não ocorre na ELA esporádica, pois não sabemos quem terá ELA. Consequentemente, devemos tomar cuidado com as extrapolações dos resultados dos estudos com animais para humanos.

Para concluir, mesmo que no momento não exista uma forma eficaz de tratar medicamentosamente a doença ELA, a tendência é de se utilizar multi-terapias (multi-drogas, terapia gênica, etc.). Com tal abordagem poderiam ser enquadrados múltiplos mecanismos patogênicos, tendo ação sobre vários alvos, podendo trazer benefícios sinérgicos. Caso funcionasse esse tipo de estratégia, teríamos uma dúvida sobre realmente qual dos tratamentos estaria realmente beneficiando, o que, em termos de ELA, do ponto de vista prático para os pacientes, não teria tanta importância, pois o que se quer é melhor ou pelo menos parar a progressão da patologia.

No momento atual, o cuidado do doente de uma forma ampla e multidisciplinar (médicos, enfermeiros, terapêutas ocupacionais, fisioterapêutas, nutricionistas, psicólogos, assistentes sociais, etc.) parecer ser mais importante que tratar somente a doença. 


\section{Referências Bibliográficas}

1.Gordon PH, Moore DH, Gelinas DF, Qualls C, Meister ME, Werner J, et al. Palcebo controlled phase I / II studies of minocycline in amyotrophic lateral sclerosis. Neurology 2004, 62: 1845-1847. 2.Pontieri FE, Ricci A, Pellicano C, Benincasa D, Buttarelli FR. Minocycline in amyotrophic lateral sclerosis: a pilot study. Neurol Sci 2005, 26: 285-287.

3.Quadros AJQ, Oliveira ASB, Silva HCA. ELA - Esclerose Lateral Amiotrófica - Atualização. Livreto informativo, Graf. RJR, São Paulo, 2006, p.22.

4.Muchowski PJ, Wacker JL. Modulation of neurodegeneration by molecular chaperones. Nat Rev Neurosci 2005, 6: 11-22.

5.Kieran D, Kalmar B, Dick JR, Riddoch-Contreras J, Burnstock G, Greensmith L. Treatment with arimoclomol, a coinducer of heart chocks proteins, delay disease progression in ALS mice. Nat Med 2004, 10 (4): 345-407. 